Research Paper

\title{
Assessment of Potential Sublethal Effects of Various Insecticides on Key Biological Traits of The Tobacco Whitefly, Bemisia tabaci
}

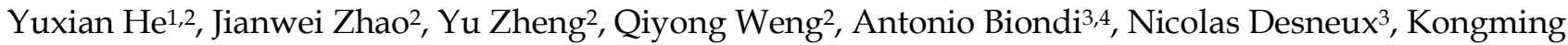 \\ $\mathrm{Wu}^{1 凶}$ \\ 1. State Key Laboratory for Biology of Plant Diseases and Insect Pests, Institute of Plant Protection, Chinese Academy of Agricultural \\ Sciences, Beijing 100193, People's Republic of China. \\ 2. Institute of Plant Protection, Fujian Academy of Agricultural Sciences, Fuzhou 350013, People's Republic of China. \\ 3. French National Institute for Agricultural Research (INRA), 400 route des chappes, 06903 Sophia Antipolis, France. \\ 4. University of Catania, Department of Agri-food and Environmental Systems Management, Via Santa Sofia 100, 95123 Catania, Italy.
}

$\square$ Corresponding author: Kong-Ming Wu, E-mail: kmwu@ippcaas.cn.

(C) Ivyspring International Publisher. This is an open-access article distributed under the terms of the Creative Commons License (http://creativecommons.org/ licenses/by-nc-nd/3.0/). Reproduction is permitted for personal, noncommercial use, provided that the article is in whole, unmodified, and properly cited.

Received: 2012.12.24; Accepted: 2013.02.20; Published: 2013.02.27

\begin{abstract}
The tobacco whitefly Bemisia tabaci is one of the most devastating pests worldwide. Current management of $B$. tabaci relies upon the frequent applications of insecticides. In addition to direct mortality by typical acute toxicity (lethal effect), insecticides may also impair various key biological traits of the exposed insects through physiological and behavioral sublethal effects. Identifying and characterizing such effects could be crucial for understanding the global effects of insecticides on the pest and therefore for optimizing its management in the crops. We assessed the effects of sublethal and low-lethal concentrations of four widely used insecticides on the fecundity, honeydew excretion and feeding behavior of $\mathrm{B}$. tabaci adults. The probing activity of the whiteflies feeding on treated cotton seedlings was recorded by an Electrical Penetration Graph (EPG). The results showed that imidacloprid and bifenthrin caused a reduction in phloem feeding even at sublethal concentrations. In addition, the honeydew excretions and fecundity levels of adults feeding on leaf discs treated with these concentrations were significantly lower than the untreated ones. While, sublethal concentrations of chlorpyrifos and carbosulfan did not affect feeding behavior, honeydew excretion and fecundity of the whitefly. We demonstrated an antifeedant effect of the imidacloprid and bifenthrin on B. tabaci, whereas behavioral changes in adults feeding on leaves treated with chlorpyrifos and carbosulfan were more likely caused by the direct effects of the insecticides on the insects' nervous system itself. Our results show that aside from the lethal effect, the sublethal concentration of imidacloprid and bifenthrin impairs the phloem feeding, i.e. the most important feeding trait in a plant protection perspective. Indeed, this antifeedant property would give these insecticides potential to control insect pests indirectly. Therefore, the behavioral effects of sublethal concentrations of imidacloprid and bifenthrin may play an important role in the control of whitefly pests by increasing the toxicity persistence in treated crops.
\end{abstract}

Key words: ecotoxicology, Electrical Penetration Graph, feeding behavior; honeydew excretion; fecundity.

\section{Introduction}

Bemisia tabaci (Gennadius) (Hemiptera: Aleyrodidae), is one of the most damaging pests worldwide [1-5], including China where, since the 1990s, it has been largely affecting many major crops 
resulting in huge yield losses every year $[6,7]$. In China, various classes of insecticides, such as organophosphates, carbamates, pyrethroids and, more recently, neonicotinoids are extensively used by growers to control B. tabaci [8]. However, it has been reported that this pest has been difficult to control with conventional and newer insecticides because of the rapid development of resistance, as a result of overuse [8-11].

In field crops, lower insecticide concentrations usually occur after the initial insecticide application [12]. These concentrations depend on how often insecticides are applied, how they are degraded by abiotic factors, such as rainfall, temperature and sunlight [12-14] and, in the case of systemic products, how fast is the plant growth [15-17]. Under field conditions, $B$. tabaci would be exposed to sublethal and low-lethal doses of insecticides and may experience certain related sublethal effects. These are defined as physiological or behavioral trait modifications in individuals that survive an exposure to toxic compounds (notably insecticides) being the toxicant dose/concentration either sublethal or lethal [18]. In addition to direct mortality by typical poisoning effects, pesticides may interfere with the feeding behavior of exposed insects by repellent, antifeedant, or reduced olfactory capacity effects [18-21].

Traditionally, pesticide efficacy assessment has relied on the determination of an acute median lethal dose/concentration. However, the effects of the newly developed insecticides are usually subtle, thus acute toxicity tests may only be a partial measure of the toxic effects $[18,22]$. The impairment of key behavioral and physiological traits may strongly affect population dynamics [23]. Therefore, accurate assessment of sublethal effects is crucial to acquire knowledge on the overall insecticide efficacy in controlling insect pest populations, as well as on their selectivity towards non-target organisms [18,24,25].

In the past three decades, a growing body of literature has aimed at assessing pesticide sublethal effects on various important biological traits of pests but, among them, feeding behavior has been scarcely investigated. Most plant-sucking organisms, notably homopteran insects, insert their piercing mouthparts (stylets) into the plant, imbibe fluids and expel honeydew. In previous studies, weight and honeydew excretion had usually been used as biological clues to assess effects of insecticides on feeding behaviors of homopteran insects, owing to the difficulties involved in measuring feeding quantitatively. The electronic penetration graph (EPG) technique was developed to record distinct phases of penetration and feeding activity in aphids [26]. The principal component of this system is an electrical circuit made by a potted plant, an electrical resistor, a voltage source, the tested insect and various thin wire connections. When the insect mouthparts penetrate into the plant tissues, the circuit is completed and a fluctuating voltage originates different waveforms. The biological meanings of the various EPG waveforms were studied per each specific feeding behavioral trait for various plant-sucking insect species, whiteflies included [27-30]. However, the majority of previous studies aimed at assessing insecticides effects on feeding behavior using the EPG technique were mainly conducted on aphids and brown planthopper, and few on the other homopteran insects, as well as on whiteflies. As phloem sap feeders, whiteflies penetrate their mouthparts into the leaf tissue, covering the distance from the epidermis to the phloem vessel intercellularly, and finally feed on substances in the sieve elements [31]. Using the EPG technique, the mechanical stylet activity, the punctures of plant cells, the salivation and the active and passive ingestion can be easily recorded and distinguished [26]. Inability to feed normally, as observed after the application of insecticides, should therefore be reflected in changes in the normal sequence of the EPG waveforms.

Mindful of this context, the aim of the present study is to assess the effects of sublethal and low-lethal concentrations of four insecticides (bifenthrin, carbosulfan, chlorpyrifos and imidacloprid) widely used to control whitefly pests $[1,8-11]$ on B. tabaci adult females. For this we first conducted a concentration-response bioassay and then, evaluated the amount of insecticides to test, we investigated the sublethal effects on fecundity, honeydew excretion activity and on the feeding behavior by the electronic penetration graph (EPG) technique. The obtained results could be useful: (i) to acquire knowledge on the subtle mechanisms of action of the tested insecticides; and (ii) to assess the full insecticidal potential of these pesticides, since they may be able to slow down $B$. tabaci population growth at low concentration through sublethal effects.

\section{Materials and Methods}

\section{Biological material}

Adults of $B$. tabaci were collected from vegetable fields at the suburbs of Fuzhou city, Fujian Province, China, during July-August 2008. Bemisia tabaci pupae and adults were identified at the specific level using morphological characters. The population was assigned to the B biotype using molecular markers (cytochrome oxidase I) according to the method of Alon et al. [32]. Individuals were used to establish a laboratory colony that was maintained for multiple generations on pesticide-free cotton plants, Gossypium hir- 
sutum L., in a growth chamber $\left(25 \pm 1{ }^{\circ} \mathrm{C}, 65 \pm 5 \% \mathrm{RH}\right.$, and 14:10 L:D).

\section{Insecticides}

All the insecticides tested in the study were of technical grade. The neonicotinoid imidacloprid (96.8\% purity) and the carbamate carbosulfan (95\% purity) were provided by Changlong Chemical Limited Company (Jiansu, China), the pyrethroid bifenthrin (95\% purity) was provided by Longdeng Chemical Limited Company (Jiansu, China) and the organophosphate chlorpyrifos $(98.9 \%$ purity) was provided by Xinnong Chemical Limited Company (Zhejiang, China). Stock solutions of all the insecticides were first prepared in acetone, and then were diluted with purified water to obtain final concentrations of the active ingredients (a.i.) as follows: imidacloprid 5, 10, 20, 40, 80 and 160 ppm (parts per million); bifenthrin 5, 10, 20, 40, 80 and $160 \mathrm{ppm}$; chlorpyrifos 50, 100, 200, 400, 800 and 1600 ppm; carbosulfan 100, 200, 400, 800, 1600 and 3200 ppm. Preliminary experiments were carried out to determine the range of insecticide concentrations, by exposing whitefly adults (from the population studied) to concentrations equal to recommended field application rates until observing mortality rates lower than $100 \%$. The acetone concentration in the insecticidal solutions finally used was $10 \mathrm{ml} \mathrm{l}^{-1}$ or lower. The insecticides were chosen for the experiments since they are widely used in conventional cotton cultivations worldwide, mainly to control whitefly pests, and because they well represent four different insecticides families, i.e. those of neonicotinoids, pyrethroids, organophosphates and carbamates [1,8-11]. These insecticide families impair different targets in exposed organisms: (i) the voltage-sensitive sodium channel on neuron membranes by pyrethroids, the acetylcholinesterase by the organophosphates and the carbamates, and (ii) the nicotinic acetylcholine receptors by the neonicotinoids.

\section{Insecticide exposure}

For the concentration-mortality response and for the honeydew excretion and fecundity assessments, the whiteflies were exposed to dry residues of the various insecticides on cotton leaves. Cotton leaves were treated using the leaf-dip bioassay, and it was carried out following the methodology described by He et al. [33]. Briefly, untreated cotton leaves were dipped for five seconds in the serial insecticide dilutions or in water plus acetone (as untreated control). Subsequently, the leaves were air-dried until all the insecticides solution droplets evaporated $(1 \mathrm{~h})$, and then leaf discs (35 $\mathrm{mm}$ of diameter) were cut and placed with their adaxial surface downwards onto agar in $35 \mathrm{~mm}$-diameter Petri dishes. Whereas, to conduct the EPG assay (see below), entire 30-day old cotton seedlings were dipped in the insecticide solutions or in water plus acetone for five seconds. Cotton seedlings were air-dried for $1 \mathrm{~h}$ prior being used for the experiments.

\section{Concentration-mortality response: $L_{50}$ and $\mathbf{L C}_{10}$}

To obtain the concentrations to be used in further experiments, the concentration-mortality regression lines, the lethal concentration $50\left(\mathrm{LC}_{50}\right)$ and $10\left(\mathrm{LC}_{10}\right)$, the whiteflies were exposed for $24 \mathrm{~h}$ to the insecticide concentrations using the method previously described (see the Insecticide exposure section). 0-2-day old $B$. tabaci female adults were anesthetized with $\mathrm{CO}_{2}$ for two seconds, and then they were carefully transferred onto the leaf discs. Each Petri dish was then covered with a perforated lid and kept upside down in a growth chamber $\left(25 \pm 1^{\circ} \mathrm{C}, 65 \pm 5 \% \mathrm{RH}\right.$ and $14: 10$ L:D). Mortality was recorded after $24 \mathrm{~h}$ of exposure and the adults were considered dead when they remained immobile after being touched by a fine paintbrush. For each treatment (i.e. the four insecticides and the untreated control) and concentration tested, six replicates of 25 whiteflies were carried out.

\section{Sublethal effects on honeydew excretion and on fecundity}

To assess the effects of the insecticides on two important B. tabaci biological traits, i.e. honeydew excretion and egg laying activity, a sublethal concentration (inducing no significant mortality when compared to the untreated control [18]) and a low-lethal concentration $(<40 \%$ mortality after 24 -h of exposure) of each insecticides were used. These concentrations were chosen based on results of the section Concentration-mortality response. More specifically, we tested 5 and $20 \mathrm{ppm}$ of imidacloprid, 10 and $40 \mathrm{ppm}$ of bifenthrin, 50 and 200 ppm of chlorpyrifos, and 100 and 400 ppm of carbosulfan. The whiteflies were exposed to the insecticides using the methodology described above with the exception that the dishes were placed upside down on filter paper imbibed in ethanol solutions containing $0.1 \%$ bromocresol green. This system allows estimating the deposited honeydew, since bromocresol green produces blue spots where honeydew droplets are deposited with their size (surface) representing the amount of honeydew secreted by the tested insects [34]. After $24 \mathrm{~h}$ of insecticides exposure, the area of blue spots on the filter paper was determined, and the adult mortality and the number of laid eggs were recorded. Five replicates of 20 0-2-day old adult females, previously starved for $2 \mathrm{~h}$, for each treatment and concentration were carried out. 


\section{Sublethal effects on feeding behavior: EPG recording and studied parameters}

The feeding behavior of the whiteflies exposed to plants treated with the sublethal and low lethal concentrations (see the Sublethal effects on fecundity and honeydew excretion section) was studied using the EPG DC (direct current) system technique [35] aiming at monitoring the whitefly stylet activity. For this we used an EPG Giga-4 amplifier (Wageningen University, Wageningen, The Netherlands) which was connected to a microcomputer. A gold wire (length: $2 \mathrm{~cm}$, diameter: $10 \mu \mathrm{m})$ was attached, with water soluble silver glue, to the notum (thoracic dorsum) of the whiteflies, and then was connected to the EPG amplifier. The tested whiteflies were placed on the abaxial surface of the treated leaf disc. After $30 \mathrm{~min}$ of acclimation, the experiment was carried out inside a Farady cage to avoid electrical noises [36] in the laboratory $\left(25 \pm 1^{\circ} \mathrm{C}, 65 \pm 5 \% \mathrm{RH}\right)$. At least 20 0-2-day old females (previously starved for $2 \mathrm{~h}$ ) per each insecticide and concentration were exposed to treated plants and tested using the EPG DC system. Behavioral observations were conducted between noon and $7.30 \mathrm{pm}$. The EPG signal was recorded during $6 \mathrm{~h}$ and the output signals were stored using the DI-720 Series $^{\circledR}$ software (DataQ Instruments, Ohio, USA). The same software was also used to analyze the various EPG behavioral waveforms recorded during the experiments. The waveforms, previously described for $B$. tabaci and correlated with the probing activity of this particular species [28,35-37], were characterized as: (i) non-probing (waveform $\mathrm{Np}$ : stylets external to the plant); (ii) pathway phase (waveforms A, B C and pd [potential drop] reflecting an intercellular stylet pathway, intracellular feeding); (iii) xylem ingestion (waveform G); and (iv) phloem activities (waveform $\mathrm{E}$ [E1 and E2] representing salivation into phloem sieve elements and phloem ingestion).

\section{Statistical analysis}

The concentration-mortality response, the $\mathrm{LC}_{50}$ and the $\mathrm{LC}_{10}$ for $\mathrm{B}$. tabaci, after 24 of exposure, were determined using a regression log-probit model [38]. Dose-mortality relationships were considered valid (i.e. they fitted the observed data) when there was absence of significant deviation between the observed and the expected data (at the $P<0.05$ level). The surface of the honeydew deposits, the number of eggs laid (fecundity) and percentage of mortality of B. tabaci adults when exposed to sublethal and low-lethal insecticides concentrations was analyzed using a one-way analysis of variance (ANOVA) followed by a HSD post hoc test for multiple comparisons with the control group. The same statistical method was used for analyzing the data obtained in the feeding behavior experiments i.e. time spent before the first probe (waveforms A, B, C, G and Pd) and phloem activities event (waveform $\mathrm{E}$ ), total time spent in non-probing (waveform $\mathrm{Np}$ ), in non- phloem (waveforms $\mathrm{Pd}, \mathrm{A}, \mathrm{B}, \mathrm{C}$ ) and in phloem activities (waveform E). All datasets were first tested for normality and homogeneity of variance using Kolmogorov-Smirnov D test and Cochran's test respectively, and transformed if needed. All analyses were conducted using SAS program [39].

\section{Results}

\section{Determination of the $L C_{50}$ and the $L C_{10}$}

Log-probit regression analyses of concentration-mortality data showed that, after $24 \mathrm{~h}$ of exposure to imidacloprid, bifenthrin, chlorpyrifos and carbosulfan, the $\mathrm{LC}_{50}$ values were estimated at 39.60 ppm, 52.35 ppm, 337.04 ppm and 632.22 ppm, respectively. Whereas, The $\mathrm{LC}_{10}$ values at $24 \mathrm{~h}$ for imidacloprid, bifenthrin, chlorpyrifos and carbosulfan were estimated at $5.28 \mathrm{ppm}, 10.02 \mathrm{ppm}, 55.18 \mathrm{ppm}$ and $128.37 \mathrm{ppm}$, respectively. Therefore, $5 \mathrm{ppm}, 10 \mathrm{ppm}$, $50 \mathrm{ppm}$ and $100 \mathrm{ppm}\left(\sim \mathrm{LC}_{10}\right)$ were selected as sublethal concentrations for further experiments for imidacloprid, bifenthrin, chlorpyrifos and carbosulfan, respectively (Table 1). Absence of significant mortality in B. tabaci adults exposed to these concentrations was confirmed during the Honeydew excretion and egg production experiments (see below).

Table I. LC 50 and $\mathrm{LC}_{10}$ values (with corresponding $95 \%$ confidence intervals) for Bemisia tabaci adults after $24 \mathrm{~h}$ of exposure to insecticide-contaminated cotton leaves. Mortality in all control groups was always below $5 \%$. The results are presented as LC 50 and LC $_{10}$ with corresponding $95 \%$ confidence intervals $(\mathrm{Cl})$, chi-square results, degree of freedom (df) and regression equations.

\begin{tabular}{lllll}
\hline & Imidacloprid & Bifenthrin & Chlorpyrifos & Carbosulfan \\
\hline Regression equations & $\mathrm{y}=2.660+1.464 \mathrm{x}$ & $\mathrm{y}=1.932+1.785 \mathrm{x}$ & $\mathrm{y}=0.878+1.631 \mathrm{x}$ & $\mathrm{y}=-0.184+1.861 \mathrm{x}$ \\
$\chi^{2}(\mathrm{df})$ & $1.8617(4)$ & $0.8544(3)$ & $0.8944(3)$ & $0.6225(3)$ \\
LC50 $(\mathrm{ppm}) 95 \% \mathrm{CI}$ & 39.60 & 52.35 & 337.04 & 632.22 \\
& $33.19-48.11$ & $45.68-62.40$ & $280.59-420.81$ & $537.25-765.53$ \\
$\mathrm{LC}_{10}(\mathrm{ppm}) 95 \% \mathrm{CI}$ & 5.28 & 10.02 & 55.18 & 128.37 \\
& $3.63-7.01$ & $7.14-12.89$ & $38.69-71.52$ & $95.81-160.23$ \\
\hline
\end{tabular}




\section{Honeydew excretion and egg production}

The sublethal concentrations caused mortality rates ranging from $3 \%$ to $9 \%$ and they were not significantly different from the mortality percentages recorded for the untreated control $\left(\mathrm{F}_{4,20}=2.645 ; \mathrm{P}\right.$ $=0.0638)$ (Fig. 1). The same concentrations caused a significant decrease of honeydew excretion only for imidacloprid and bifenthrin, 20.59 and $7.40 \mathrm{~mm} 2$, respectively $\left(\mathrm{F}_{4,20}=4.512 ; \mathrm{P}=0.007\right)$ (Fig. 2). By contrast, sublethal concentrations of chlorpyrifos and carbosulfan did not significantly decrease honeydew secretion of $B$. tabaci. The same trend was observed for the fecundity; only the sublethal concentrations of imidacloprid and bifenthrin significantly reduced the number of eggs laid by adults (about by one third and a half, respectively) during the 24-h exposure period $\left(\mathrm{F}_{4,20}=9.398 ; \mathrm{P}<0.001\right)$ (Fig. 3).
The mortality rates caused of the low-lethal concentrations ranged from $24 \%$ to $35 \%$ for chlorpyrifos and carbosulfan, respectively (Fig. 1), and the mortality caused by all the insecticides was significantly different from the untreated control one $\left(\mathrm{F}_{4,20}=\right.$ 11.439; $\mathrm{P}<0.001)$. Honeydew excretion and egg production significantly decreased when B. tabaci adults were exposed to the low-lethal concentrations of all the tested insecticides (honeydew excretion: $\mathrm{F}_{4,20}=$ 40.114; $\mathrm{P}<0.001$. Egg production: $\mathrm{F}_{4,20}=30.961 ; \mathrm{P}<$ 0.001) (Fig. 2 and 3). The most detrimental chemical was bifenthrin that caused the lowest honeydew excretion and fecundity levels, $0.40 \mathrm{~mm}^{2}$ and 37.20 eggs laid, respectively. Although significantly different from the control, the results obtained with chlorpyrifos at $200 \mathrm{ppm}$ were the highest, i.e. $11.90 \mathrm{~mm}^{2}$ of honeydew deposits and 93.20 laid eggs (Fig. 2 and 3).

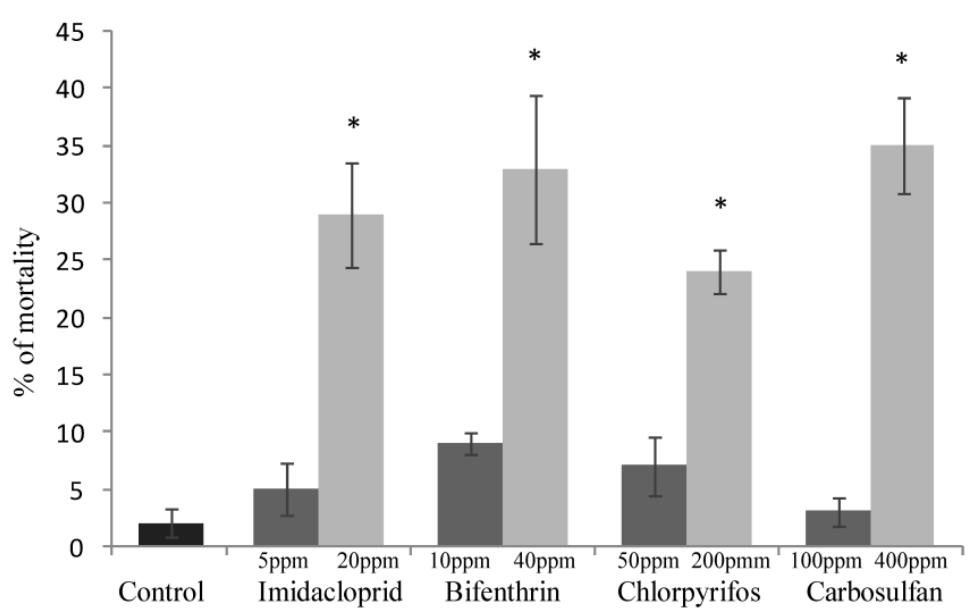

Figure I. Lethal effect of sublethal and low-lethal insecticide concentrations. Percentages (means \pm SEM) of Bemisia tabaci females after $24 \mathrm{~h}$ of exposure to sublethal and low-lethal concentrations of the four tested insecticides. Means for treatment bearing asterisks differed from the untreated control at $P<0.05$, one-way ANOVA followed by HSD test.

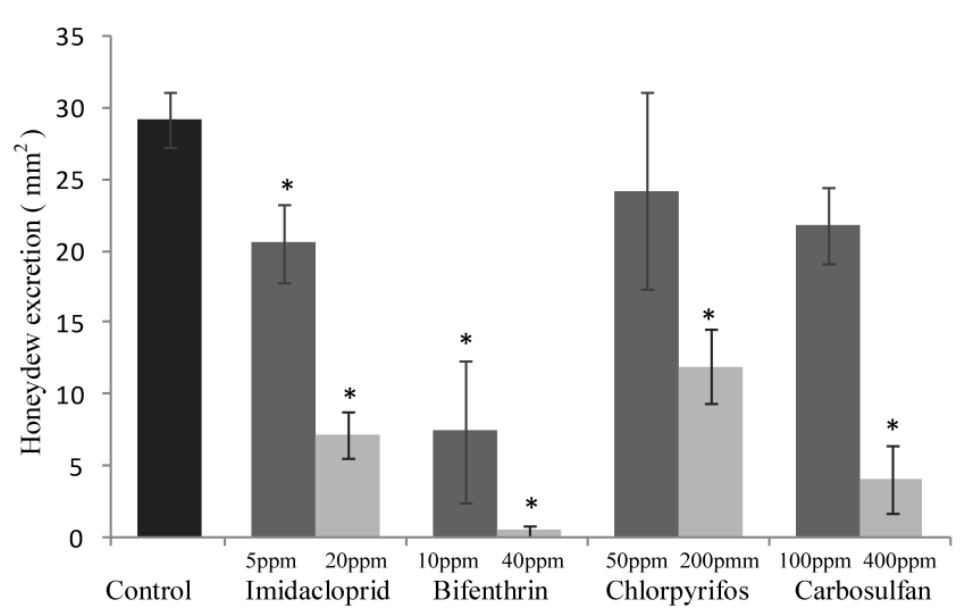

Figure 2. Sublethal effect on honeydew excretion of sublethal and low-lethal insecticide concentrations. Means ( \pm SEM) of honeydew excretion deposited by Bemisia tabaci females, measured as blue spots size $\left(\mathrm{mm}^{2}\right)$ on bromocresol green after $24 \mathrm{~h}$ of exposure to sublethal and low-lethal concentrations of the four tested insecticides. Means for treatment bearing asterisks differed from the untreated control at $P<0.05$, one-way ANOVA followed by HSD test. 


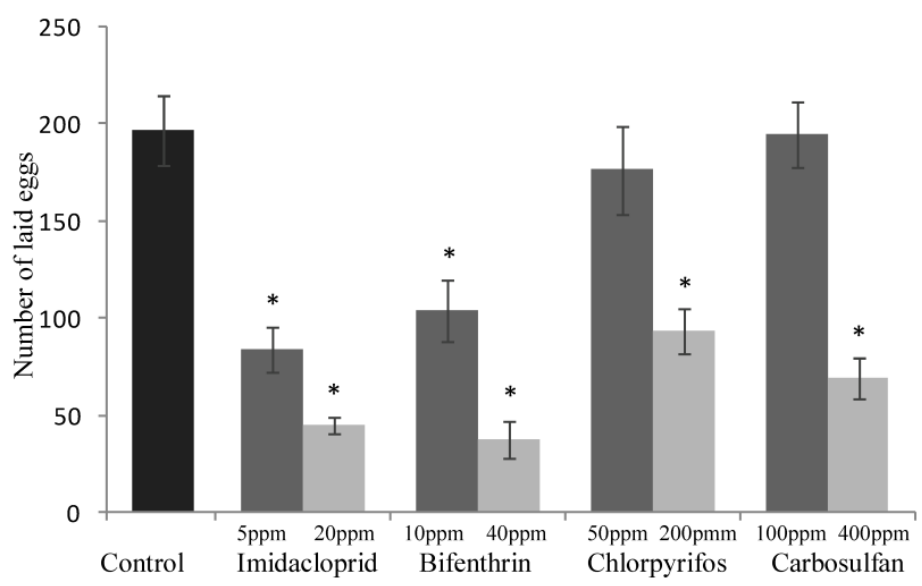

Figure 3. Sublethal effect on egg production of sublethal and low-lethal insecticide concentrations. Total number of laid eggs (means \pm SEM) by Bemisia tabaci females after $24 \mathrm{~h}$ of exposure to sublethal and low-lethal concentrations of the four tested insecticides. Means for treatment bearing asterisks differed from the untreated control at $P<0.05$, one-way ANOVA followed by HSD test.
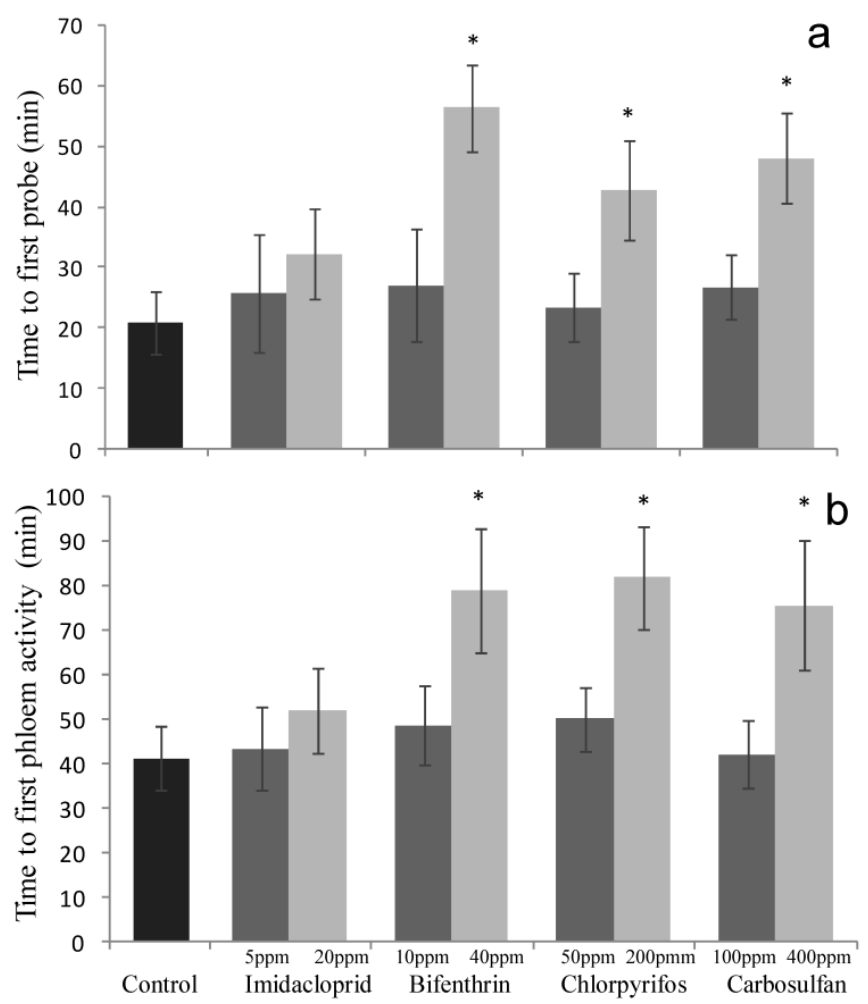

Figure 4. Sublethal effect on feeding behavior of sublethal and low-lethal insecticide concentrations. Means ( $\pm S E M)$ of minutes spent by Bemisia tabaci females before the first (a) probing (waveforms A, B, C and Pd) and (b) phloem (waveform E) activities, during the 6-h behavioral bioassay conducted on leaves treated with sublethal and low-lethal concentrations of the four tested insecticides. Means for treatment bearing asterisks differed from the untreated control at $P<0.05$, one-way ANOVA followed by HSD test.

\section{Feeding behavior}

In the 6-h period of recorded EPGs, we observed typical waveforms of $B$. tabaci feeding on cotton leaves [37], such as non-probing (waveform $\mathrm{Np}$ ), pathway phase (waveforms $\mathrm{A}, \mathrm{B}, \mathrm{C}$, and $\mathrm{Pd}$ ), xylem ingestion (waveform G), and phloem activities (waveform E).
However, since xylem ingestion occurred very rarely in the EPGs, it was not analyzed further.

The time spent before the first probing event was significantly altered only after exposure to low-lethal concentrations of bifenthrin, chlorpyrifos and carbosulfan $\left(\mathrm{F}_{4,95}=4.44 ; \mathrm{P}=0.002\right)$ (Fig. $\left.4 \mathrm{a}\right)$. In particular, when compared to the untreated control, the corre- 
sponding time intervals increased by 35.44, 21.84 and 27.1 minutes, respectively. By contrast, this trait was not significantly affected when exposing the whiteflies to sublethal concentrations of all the insecticides tested $\left(\mathrm{F}_{4,103}=0.173 ; \mathrm{P}=0.952\right)$ (Fig. $\left.4 \mathrm{a}\right)$. The same trend (i.e. only low-lethal concentrations of bifenthrin, chlorpyrifos and carbosulfan caused significant effects) was recorded when analyzing the time spent before the first phloem feeding $\left(\mathrm{F}_{4,95}=3.576 ; \mathrm{P}=0.009\right)$ (Fig. 4b). By contrast, sublethal concentrations of all the tested insecticides did not affect this parameter $\left(\mathrm{F}_{4,103}=0.231 ; \mathrm{P}=0.920\right)$ (Fig. $\left.4 \mathrm{~b}\right)$.

On the other hand, when the total durations (for the $6 \mathrm{~h}$ of observations) of the single traits of the $B$.
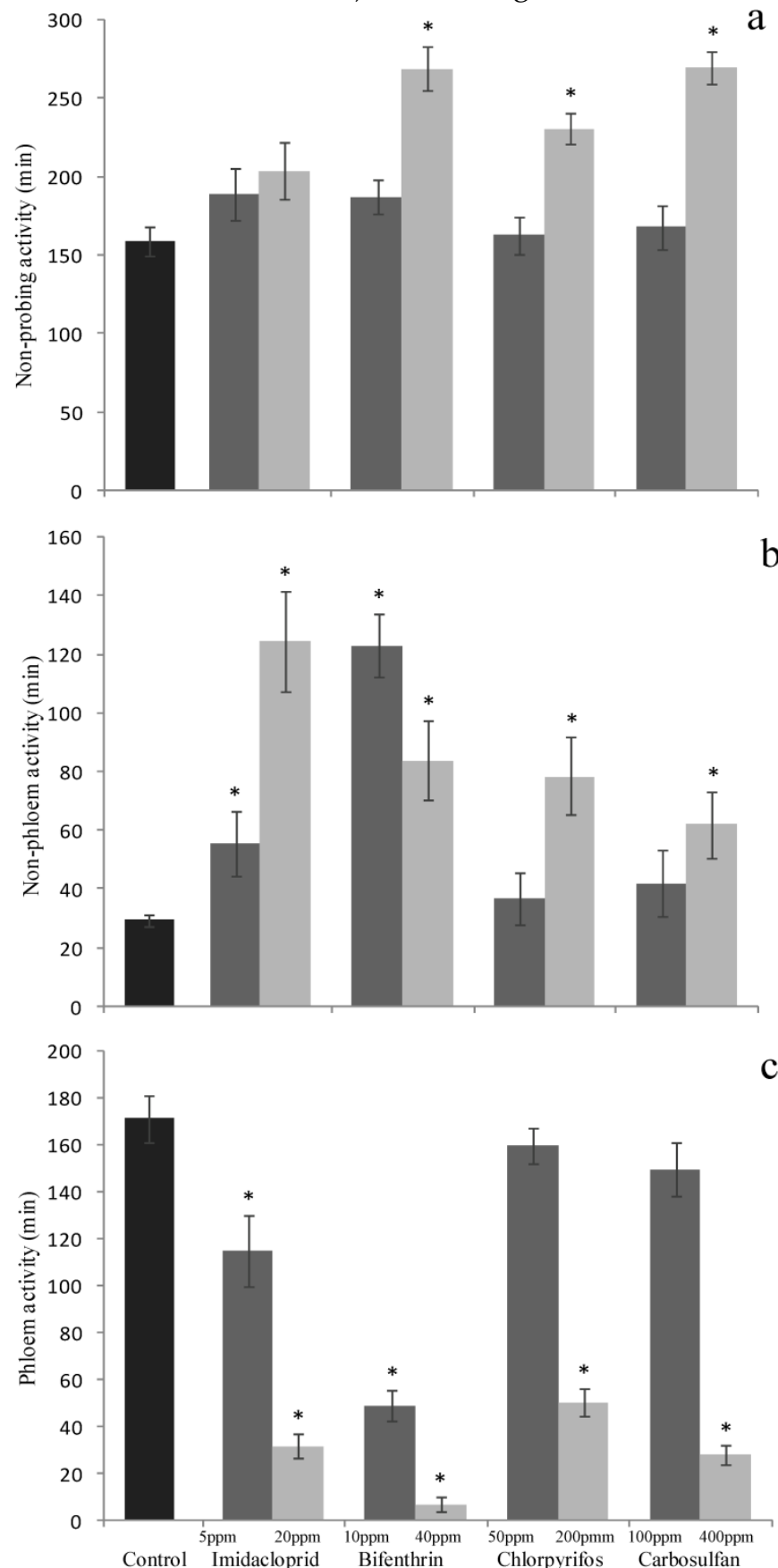

tabaci feeding behavior were studied, sublethal concentrations of imidacloprid and bifenthrin both decreased the duration of the phloem activity $\left(\mathrm{F}_{4,103}=\right.$ 16.821; $\mathrm{P}<0.001$ ) (Fig. 5c) and increased the non-phloem activity durations $\left(\mathrm{F}_{4,103}=35.637\right.$; $\mathrm{P}<0.001$ ) (Fig. 5b), this resulting in a marked decrease of the overall feeding activities. The total duration of the non-probing behavior was not significantly affected by sublethal concentrations of imidacloprid and bifenthrin $\left(\mathrm{F}_{4,103}=1.269 ; \mathrm{P}=0.287\right)$ (Fig. 5a). By contrast, chlorpyrifos and carbosulfan at sublethal concentrations did not affect all these traits and the various recorded time intervals were similar to those recorded for the whiteflies exposed to insecticide-free cotton leaves (Fig. 5a, 5b and 5c).

The low-lethal concentrations of bifenthrin, chlorpyrifos and carbosulfan significantly affected the duration of the non-probing $\left(\mathrm{F}_{4,95}=17.02 ; \mathrm{P}<0.001\right)$ (Fig. 5a), non-phloem $\left(\mathrm{F}_{4,95}=17.305 ; \mathrm{P}<0.001\right)$ (Fig. 5b) and phloem behaviors $\left(\mathrm{F}_{4,95}=55.403 ; \mathrm{P}<0.001\right)$ (Fig. $5 c)$. The increase of durations of non-probing (chlorpyrifos: +72 min., bifenthrin and carbosulfan: + $\sim 110 \mathrm{~min}$.) and non-phloem activities (55, 49, $33 \mathrm{~min}$. for bifenthrin, chlorpyrifos and carbosulfan, respectively) caused a marked decrease of the feeding activity sensu stricto, i.e. of the phloem activities $(-165,-121$ and-143 minutes for bifenthrin, chlorpyrifos and carbosulfan, respectively). Imidacloprid at the low-lethal dose did not affect significantly the non-probing behavior (Fig. 5a), but significantly increased the duration of non-phloem activity (+95 minutes) (Fig. 5b) and decreased the amount of time spent for phloem feeding (-140 minutes) (Fig. 5c).

Figure 5. Sublethal effect on probing behavior of sublethal and low-lethal insecticide concentrations. Means $( \pm$ SEM) of total time (minutes) spent by Bemisia tabaci in (a) non-probing (waveform Np), (b) non-phloem (waveforms $A, B, C$ and $\mathrm{Pd}$ ) and (c) phloem (waveform E) activities, during the 6-h behavioral bioassay on leaves treated with sublethal and low-lethal concentrations of the four tested insecticides. Means for treatment bearing asterisks differed from the untreated control at $P<$ 0.05 , one-way ANOVA followed by HSD test.

\section{Discussion}

In addition to direct mortality induced by pesticides, insects that survive to an exposure to these products may experience behavioral and/or physiological alterations [18]. This is particularly true in the case of newly developed insecticide which has a slower mode of action and may produce a greater degree of sublethal effects rather than acute ones [18, 22-24]. In the present study we assessed the effects of 
insecticides belonging to four different chemical families and we provided experimental evidence of sublethal effects induced by the four insecticides on $B$. tabaci adults. Interestingly, imidacloprid and bifenthrin caused major sublethal effects on both reproduction and feeding-related traits even when applied at sublethal concentrations, i.e. at rates of insecticides that do not cause significant insect mortality. By contrast, chlorpyrifos and carbosulfan affected physiological and behavioral traits only when $B$. tabaci were exposed to higher (low-lethal) concentrations. Interestingly, no stimulatory effects of low concentrations were found in any of the tested insecticide. This phenomenon, known as hormesis, has been proved to occur on both pest and natural enemy insects after the exposure to low doses of some insecticides, such as imidacloprid $[25,40]$. The obtained results show that the effects of the insecticides can strongly vary depending upon various factors, such as the endpoint considered (mainly lethal, physiological and behavioral), the insecticide chemical family and the insecticide concentration considered.

Severe detrimental effects on the whitefly fecundity were observed in individuals feeding on cotton leaves treated with the imidacloprid and bifenthrin at sublethal concentrations, and with all the tested insecticides at low-lethal concentrations. Reduced fecundity of the whitefly after feeding on leaves treated with sublethal concentration of imidacloprid is consistent with previous works studying other Hemipteran insect species. The fecundity of aphid species (Myzus persicae (Sulzer) and M. nicotianae Blackman) and leafhopper species (Nephotettix cincticeps (Uhler), N. virescens (Distant) and Nilaparvata lugens (Stal)) was reduced by more than $50 \%$ after feeding on plants/leaves treated with sublethal concentrations of imidacloprid [41-43]. Similar reproductive effects of pyrethroids had been also reported for mite Tetranychus urticae Koch [44] and thrips Frankliniella occidentalis (Pergande) [45]. Reproduction related traits have traditionally been the most sublethal parameter studied and represent one of the most important life-history when studying the insect population levels [13,18,21-23]. Therefore, the obtained results may be of primary importance for the management of pests in crops.

Comparing the reductions in honeydew excretion of whitefly feeding on imidacloprid-, bifenthrin-, chlorpyrifos- and carbosulfan-treated leaves, it arises that honeydew excretion was decreased by imidacloprid and bifenthrin even when applied at sublethal concentration (i.e. $\mathrm{LC}_{10}$ in our study). In a previous study, imidacloprid gave similar results since the Asian citrus psyllid (Diaphorina citri Kuwayama) adults excreted significantly less honeydew, when they fed on citrus leaves treated systemically with lethal and sublethal concentrations of imidacloprid [46]. By contrast, in our study, sublethal concentrations of chlorpyrifos and carbosulfan did not cause reduction in the honeydew excretion of whitefly adults remarkably. Furthermore, the decrease in honeydew excretion of whitefly adults feeding on leaves treated with low-lethal concentrations of chlorpyrifos (200 ppm) and carbosulfan (400 ppm) may be linked to the observed mortality and pre-lethal typical symptoms of poisoning by insecticides in arthropods. The results obtained for imidacloprid are in accordance with those of a previous study, in which, although female adults of $B$. tabaci preferred untreated leaf discs rather than the treated ones, the honeydew excretion was inhibited by $50 \%$ when whiteflies fed on leaves treated even with very low imidacloprid concentrations, i.e. 150- to 850-times lower than the $\mathrm{LC}_{50}$ [47].

Honeydew excretion is a physiological process that originates from the feeding activity, since honeydew is expelled from the gut's terminal opening after that the mouthpart penetrates the phloem. Therefore, whitefly-feeding data, obtained with the EPG analysis, may help in understanding the mechanism of the antifeedant properties of the studied chemicals. Indeed, feeding behavior results were well correlated with the amount of honeydew secreted, since at sublethal concentrations only imidacloprid and bifenthrin caused significant behavioral changes of $B$. tabaci and, at low-lethal concentrations, all the tested insecticides impaired the feeding activity. Whiteflies exposed to sublethal concentrations did not delay their first phloem activities (Fig. 4b) and, after being in contact with the treated plant sap, they significantly reduced the phloem activity (Fig. 5c) and increased the non-phloem one (Fig. 5b). This clearly proves that the insecticides did not have repellency proprieties, since the insects were not repulsed by the treated leaves, while they act as antifeedant, i.e. decreasing the feeding of the pest. Similar antifeedant effects of imidacloprid have been reported on other plant sucking insects, such as the aphids M. nicotianae and M. persicae [27,41]. Daniels et al. [29] and Cui et al. [30] also found that sublethal dose of thiamethoxam and IPP10 (a novel neonicotinoid), caused reduction in xylem and phloem feeding by Rhopalosiphum padi (L.) on wheat. Antifeedant activity of pyrethroids was reported for other sucking insects, such as mite T. urticae adults [44], and thrips F. occidentalis adults [45]. For organophosphates and carbamates, carbosulfan at $0.5 \mathrm{ppm}\left(\mathrm{LC}_{50} 2.9 \mathrm{ppm}\right)$ and methiocarb at $\leq 5$ ppm ( $\mathrm{LC}_{50} 52.6 \mathrm{ppm}$ ) suppressed the feeding of 
F. occidentalis. Methamidophos and monocrotophos also inhibited the feeding activity of immature instars of this thrip species at concentrations less than the $\mathrm{LC}_{10}$ [45]. By contrast, T. urticae behavior appeared to be unaffected by phosmet [44].

We assume that the antifeeding response of $B$. tabaci exposed to imidacloprid and bifenthrin may be related to the effects on the epipharyngeal chemoreceptors (through altered cibarial pump activity and overall decreased capacity to ingest xylem sap). Indeed, studies suggest a possible negative effect of another neonicotinoid, the thiamethoxam, on the cibarial pump in aphid species [30]. This negative effect on the cibarial pump may be due to a neurotoxic effect on either the pharyngeal valve or the dilator muscles, which are innervated via the thoracic ganglion [48]. Luo et al. [49] reported that toosendanin, a triterpenoid derivative, inhibits the sugar and the glucosinolate receptors in the epipharyngeal sensillum (the lateral styloconicum). McLean and Kinsey [26] also reported that negative stimulation of the gustatory epipharyngeal sensilla, which are located in the epipharyngeal gustatory organ, may initiate the relaxation of either the cibarial pump muscles or the pharyngeal valve, thus slowing ingestion and resulting in an antifeedant effect. Moreover, another hypothesis is plant composition changes induced by imidacloprid and bifenthrin, e.g. due to alterations in the amino acid composition, which could also inhibit ingestion by the whiteflies. Indeed, $\mathrm{Wu}$ et al. [50] found that, although the total free amino acid composition was not affected by the pesticide treatment, some amino acids were significantly altered after pesticide application, as exemplified by lower $\gamma$-aminobutyric acid, bisultap and jingganmycin in treated plants than that in the untreated ones.

Taken as a whole, the results show that aside from the lethal effect, sublethal concentration of imidacloprid and bifenthrin modify whitefly behavior by impairing phloem feeding, the most important feeding trait in a plant protection perspective. Indeed, this pest causes direct crop damage through phloem feeding (sap suction) and indirectly through honeydew contamination and associated fungal growth, or by vectoring several plant viruses plant injuries (infected saliva inoculation) [1,3] and the successful virus transmission is often enhanced by an increase of B. tabaci phloem feeding duration [51]. Therefore, the antifeedant property of imidacloprid and bifenthrin sublethal doses would give these insecticides potential to control insect pests indirectly, or at least to reduce their negative effects on the crops.

However, although this study showed that some biological traits of whiteflies are still affected even at low concentrations, the impact on other life history traits of this insect needs to be evaluated before deployment in this sense. Meanwhile, a long-term study should evaluate the potential sublethal effects on the broader insect community under field conditions, especially on natural enemies of B. tabaci. Sublethal effects can impair various key processes of the natural enemies' efficacy against pests [52-58]. Studies on the effects of pesticides on natural enemies often aim at assessing the suitability of pesticides for Integrated Pest Management (IPM), therefore an appreciation of the lethal and sublethal effects on natural enemies as well would help to optimize IPM programmes involving use of both natural enemies and pesticides against pests like whiteflies in cotton $[18,59]$.

\section{Acknowledgements}

This research was funded by financial assistance from the Chinese Ministry of Science and Technology (2013CB127600) and Fujian Science and Technology Agency of China (2008J0062).

\section{Competing Interests}

The authors have declared that no competing interest exists.

\section{References}

1. Oliveira M, Henneberry $\mathrm{T}$, Anderson P. History, current status, and collaborative research projects for Bemisia tabaci. Crop Prot. 2001; 20: 709-723.

2. González-Zamora J, Moreno R. Model selection and averaging in the estimation of population parameters of Bemisia tabaci (Gennadius) from stage frequency data in sweet pepper plants. J Pest Sci. 2011; 84: 165-177.

3. De Barro PJ, Liu SS, Boykin LM, et al. Bemisia tabaci: a statement of species status. Ann Rev Entomol. 2011; 56: 1-19.

4. do Valle GE, Lourenc AL, Pinheiro JB. Adult attractiveness and oviposition preference of Bemisia tabaci biotype B in soybean genotypes with different trichome density. J Pest Sci. 2012; 85: 431-442.

5. Jiao X, Xie W, Wang S, et al. Host preference and nymph performance of $B$ and $Q$ putative species of Bemisia tabaci on three host plants. J Pest Sci. 2012; 85: 423-430.

6. Ren SX, Wang ZX, Qiu BL, et al. The pest status of Bemisia tabaci in China and non-chemical control strategies. Entomol Sinica. 2001; 8: 279-288.

7. Qiu BL, Dang F, Li SJ, et al. Comparison of biological parameters between the invasive B biotype and a new defined Cv biotype of Bemisia tabaci (Hemiptera: Aleyradidae) in China. J Pest Sci. 2011; 84: 419-427.

8. Liang P, Tian YA, Biondi A, et al. Short-term and transgenerational effects of the neonicotinoid nitenpyram on susceptibility to insecticides in two whitefly species. Ecotoxicology. 2012; 21: 889-1898.

9. He YX, Weng QY, Huang J, et al. Insecticide resistance of Bemisia tabaci field populations. Chin J Appl Ecol. 2007; 18: 1578-1582.

10. Ahmad M, Arif M, Naveed M. Dynamics of resistance to organophosphate and carbamate insecticides in the cotton whitefly Bemisia tabaci (Hemiptera: Aleyrodidae) from Pakistan. J Pest Sci. 2010; 83: 409-420.

11. Zheng $Y$, Zhao JW, He YX, et al. Development of insecticide resistance and its effect factors in field population of Bemisia tabaci in Fujian Province, East China. Chin J Appl Ecol. 2012; 23: 271-277.

12. Desneux N, Fauvergue X, Dechaume-Moncharmont FX, et al. Diaeretiella rapae limits Myzus persicae populations after applications of deltamethrin in oilseed rape. J Econ Entomol. 2005; 98: 9-17.

13. Biondi A, Desneux N, Siscaro G, et al. Using organic-certified rather than synthetic pesticides may not be safer for biological control agents: Selectivity and side effects of 14 pesticides on the predator Orius laevigatus. Chemosphere. 2012; 87: 803-812. 
14. Vanaclocha P, Vidal-Quist C, Oheix S, et al. Acute toxicity in laboratory tests of fresh and aged residues of pesticides used in citrus on the parasitoid Aphytis melinus. J Pest Sci. 2012; DOI:10.1007/s10340-012-0448-8.

15. Laurent FM, Rathahao E. Distribution of [14C] imidacloprid in sunflowers (Helianthus annuus L.) following seed treatment. J Agric Food Chem. 2003; 51: 8005-8010.

16. Bonmatin JM, Marchand PA, Charvet R, et al. Quantification of imidacloprid uptake in maize crops. J Agric Food Chem. 2005; 53: 5336-5341.

17. Zhang LP, Greenberg SM, Zhang YM, et al. Effectiveness of thiamethoxam and imidacloprid seed treatments against Bemisia tabaci (Hemiptera: Aleyrodidae) on cotton. Pest Manag Sci. 2011; 67: 226-232.

18. Desneux N, Decourtye A, Delpuech JM. The sublethal effects of pesticides on beneficial arthropods. Ann Rev Entomol. 2007; 52: 81-106.

19. Han P, Niu CY, Lei CL, et al. Quantification of toxins in a Cry1Ac+ CpTI cotton cultivar and its potential effects on the honey bee Apis mellifera L. Ecotoxicology. 2010; 19: 1452-1459.

20. Han P, Niu CY, Lei CL, et al. Use of an innovative T-tube maze assay and the proboscis extension response assay to assess sublethal effects of GM products and pesticides on learning capacity of the honey bee Apis mellifera L. Ecotoxicology. 2010; 19: 1612-1619.

21. Zappalà L, Siscaro G, Biondi A, et al. Efficacy of sulphur on Tuta absoluta and its side effects on the predator Nesidiocoris tenuis. J Appl Entomol. 2012; 136: 401-409.

22. Wennergren U, Stark J. Modeling long-term effects of pesticides on populations: beyond just counting dead animals. Ecol Appl. 2000; 10: 295-302.

23. Stark JD, Banks JE, Vargas R. How risky is risk assessment: The role that life history strategies play in susceptibility of species to stress. Proc Nat Acad Sci USA. 2004; 101:732-736.

24. Biondi A, Mommaerts V, Smagghe G, et al. The non-target impact of spinosyns on beneficial arthropods. Pest Manag Sci. 2012; 68: 1523-1536.

25. Tan Y, Biondi A, Desneux N, et al. Assessment of physiological sublethal effects of imidacloprid on the mirid bug Apolygus lucorum (Meyer-Dür). Ecotoxicology. 2012; 21: 1989-1997.

26. McLean DL, Kinsey MG. A Technique for electronically recording aphid feeding and salivation. Nature. 1964; 202: 1358-1359.

27. Nauen R. Behaviour modifying effects of low systemic concentrations of imidacloprid on Myzus persicae with special reference to an antifeeding response. Pestic Sci. 1995; 44: 145-153.

28. Gao QG, Luo C, Guo XJ, et al. EPG-recorded probing and feeding behaviors of Bemisia tabaci and Trialeurodes vaporariorum on cabbage. Chin Bull Entomol. 2006; 43: 802-805.

29. Daniels M, Bale J, Newbury H, et al. A sublethal dose of thiamethoxam causes a reduction in xylem feeding by the bird cherry-oat aphid (Rhopalosiphum padi), which is associated with dehydration and reduced performance. J Insect Physiol. 2009; 55: 758-765.

30. Cui L, Sun LN, Shao XS, et al. Systemic action of novel neonicotinoid insecticide IPP-10 and its effect on the feeding behaviour of Rhopalosiphum padi on wheat. Pest Manag Sci. 2010; 66: 779-785.

31. Pollard DG. Feeding habits of the cotton whitefly, Bemisia tabaci Genn. (Homoptera: Aleyrodidae). Ann Appl Biol. 1955; 43: 664-671.

32. Alon M, Benting J, Lueke B, et al.Multiple origins of pyrethroid resistance in sympatric biotypes of Bemisia tabaci (Hemiptera: Aleyrodidae). Insect Biochem Mol Biol. 2006; 36: 71-79.

33. He YX, Zhao JW, Wu DD, et al. Sublethal effects of imidacloprid on Bemisia tabaci (Hemiptera: Aleyrodidae) under laboratory conditions. J Econ Entomol. 2011; 104: 833-838.

34. Zhao JW, He YX, Weng QY, et al. Effects of host plants on selection behavior and biological parameters of Bemisia tabaci Gennadius biotype B. Chin J Appl Ecol. 2009; 20: 2249-2254.

35. Johnson DD, Walker GP. Intracellular punctures by the adult whitefly Bemisia argentifolii on DC and AC electronic feeding monitors. Entomol Exp Appl. 1999; 92: 257-270.

36. Yue M, Luo C, Xu H. Gluing techniques of gold wire electrode to Bemisia tabaci in electrical penetration graph. Chin Bull Entomol. 2005; 42: 326-328.

37. Liu BM, Yan FM, Chu D, et al. Difference in feeding behaviors of two invasive whiteflies on host plants with different suitability: implication for competitive displacement. Int J Biol Sci 2012; 8: 697-706.

38. Finney D. Probit analysis. London, UK: Cambridge University. 1971: 333.

39. SAS. SAS/STAT user's guide, Version 8. Cary, NC: SAS Institute Inc. 2000.

40. Calabrese EJ, Blain R. The occurrence of hormetic dose responses in the toxicological literature, the hormesis database: an overview. Toxicol Appl Pharm. 2005; 202: 289-301.
41. Devine GJ, Harling ZK, Scarr AW, et al. Lethal and sublethal effects of imidacloprid on nicotine-telerant Myzus incotianae and Myzus persicae. Pestic Sci. 1996; 48: 57-62.

42. Widiarta IN, Matsumura M, Suzuki Y, et al. Effects of sublethal doses of imidacloprid on the fecundity of green leafhoppers, Nephotettix spp.(Hemiptera: Cicadellidae) and their natural enemies. Appl Entomol Zool. 2001; 36: 501-507.

43. Bao HB, Liu SH, Gu JH, et al. Sublethal effects of four insecticides on the reproduction and wing formation of brown planthopper, Nilaparvata lugens. Pest Manag Sci. 2009; 65: 170-174.

44. Iftner DC, Hall FR, Sturm MM. Effects of residues of fenvalerate and permethrin on the feeding behaviour of Tetranychus urticae (Koch). Pestic Sci. 1986; 17: 242-248.

45. Kontsedalov S, Weintraub P, Horowitz A, et al. Effects of insecticides on immature and adult western flower thrips (Thysanoptera: Thripidae) in Israel. J Econ Entomol. 1998; 91: 1067-1071.

46. Boina DR, Onagbola EO, Salyani M, et al. Antifeedant and sublethal effects of imidacloprid on Asian citrus psyllid, Diaphorina citri. Pest Manag Sci. 2009; 65: 870-877.

47. Nauen R, Koob B, Elbert A. Antifeedant effects of sublethal dosages of imidacloprid on Bemisia tabaci. Entomol Exp Appl. 1998; 88: 287-293.

48. Kaufmann L, Schürmann F, Yiallouros M, et al. The serotonergic system is involved in feeding inhibition by pymetrozine. Comparative studies on a locust (Locusta migratoria) and an aphid (Myzus persicae). Comp Biochem Physiol C Toxicol Pharmacol. 2004; 138: 469-483.

49. Luo LE, van Loon JJA, Schoonhoven L. Behavioural and sensory responses to some neem compounds by Pieris brassicae larvae. Physiol Entomol. 1995; 20: 134-140.

50. Wu JC, Xu JX, Yuan SZ, et al. Pesticide-induced susceptibility of rice to brown planthopper Nilaparvata lugens. Entomol Exp Appl. 2001; 100: 119-126.

51. Jiang YX, Blas C, Barrios L, et al. Correlation between whitefly (Homoptera: Aleyrodidae) feeding behavior and transmission of tomato yellow leaf curl virus. Ann Entomol Soc Am. 2000; 93: 573-579.

52. He $Y X$, Zhao JW, Zheng $Y$, et al. Lethal effect of imidacloprid on the coccinellid predator Serangium japonicum and sublethal effects on predator voracity and on functional response to the whitefly Bemisia tabaci. Ecotoxicology. 2012; 21: 1291-1300.

53. Arnó J, Gabarra R. Side effects of selected insecticides on the Tuta absoluta (Lepidoptera: Gelechiidae) predators Macrolophus pygmaeus and Nesidiocoris tenuis (Hemiptera: Miridae). J Pest Sci. 2011; 84: 513-520.

54. Desneux N, Rafalimanana H, Kaiser L. Dose-response relationship in lethal and behavioural effects of different insecticides on the parasitic wasp Aphidius ervi. Chemosphere. 2004; 54: 619-627.

55. Desneux N, Ramirez-Romero R, Kaiser L. Multistep bioassay to predict recolonization potential of emerging parasitoids after a pesticide treatment. Environ Toxicol Chem. 2006; 25: 2675-2682.

56. Cordeiro EMG, Corrêa AS, Venzon M, et al. Insecticide survival and behavioral avoidance in the lacewings Chrysoperla externa and Ceraeochrysa cubana. Chemosphere. 2010; 81: 1352-1357.

57. Cabral S, Soares A, Garcia P. Voracity of Coccinella undecimpunctata: effects of insecticides when foraging in a prey/plant system. J Pest Sci. 2011; 84: 373-379.

58. Stara J, Ourednickova J, Kocourek F. Laboratory evaluation of the side effects of insecticides on Aphidius colemani (Hymenoptera: Aphidiidae), Aphidoletes aphidimyza (Diptera: Cecidomyiidae), and Neoseiulus cucumeris (Acari: Phytoseidae). J Pest Sci. 2011; 84: 25-31.

59. Lu Y, Wu K, Jiang Y, et al. Widespread adoption of Bt cotton and insecticide decrease promotes biocontrol services. Nature. 2012; 487: 362-365. 